\title{
Cinética de produção de bebida mista de mel de abelha e morango
}

\section{Kinetics of mixed beverage production of honey from bees and strawberries}

\author{
Rafaela Teixeira Rodrigues do Vale Costa ${ }^{1}$, Jéssica Leite da Silva ${ }^{2}$, Ana Marinho do Nascimento ${ }^{3}$, Márcia Virgínio Souto ${ }^{4}$
}

Resumo: O morango é um fruto de estrutura frágil e muito perecível. Uma alternativa para agregar valor ao fruto é a produção de um fermentado de morango. O mel de abelha é conhecido como ingrediente versátil e altamente fermentável que apresenta sabor e aroma característico.. O presente trabalho teve como objetivo produzir uma bebida mista de mel de abelha e morango, com teor alcoólico de $10^{\circ} \mathrm{GL}$ e avaliando a cinética de fermentação alcoólica na produção da bebida. A bebida mista de mel de abelha e morango foi obtida seguindo etapas de seleção, sanitização, preparo do mosto, sulfitação, inoculação, fermentação, trasfega, clarificação, envase, rotulagem e armazenamento. O processo fermentativo foi avaliado em oito tempos de fermentação quanto ao teor de sólidos solúveis totais, produção de etanol, acidez titulável, pH e contagem de células. A bebida produzida apresentou um sabor seco com leve aroma de morango, $\mathrm{pH}$ de 3,18 , acidez titulável de $0,5 \%$ e teor alcoólico de 10,1 ${ }^{\circ} \mathrm{GL}$ estando em conformidade com os padrões exigidos pela legislação brasileira sobre bebidas. O morango e o mel de abelha utilizados na produção da bebida mista apresentou características adequadas para o processamento industrial, a graduação alcoólica da bebida mista de mel de abelha e morango foi de $10,1^{\circ} \mathrm{GL}$, estando dentro das especificações exigidas pela legislação brasileira. A produção de bebida mista de mel de abelha e morango é tecnicamente viável em função da qualidade do produto e pode ser considerada como uma forma promissora de aproveitamento do mel nos excedentes da safra.

Palavras-chave: Fermentado; Fragaria ananassa; Apis mellifera; Saccharomyces cerevisiae.

Abstract: The strawberry is a fruit of fragile and very perishable structure. An alternative to add value to the fruit is the production of a strawberry fermented. Bee honey is known as a versatile and highly fermentable ingredient that has a characteristic flavor and aroma. The present work had as objective to produce a mixed drink of honey of strawberry and honey, with alcohol content of $10^{\circ} \mathrm{GL}$ and evaluating the kinetics of fermentation In the production of the beverage. The mixed drink of honey and strawberry honey was obtained following the steps of selection, sanitization, preparation of the must, sulphitation, inoculation, fermentation, racking, clarification, packaging, labeling and storage. The fermentation process was evaluated in eight fermentation times for the total soluble solids content, ethanol production, titratable acidity, $\mathrm{pH}$ and cell count. The beverage produced had a dry flavor with a slight strawberry flavor, $\mathrm{pH}$ of 3.18 , titratable acidity of $0.5 \%$ and alcohol content of $10.1^{\circ} \mathrm{GL}$ in compliance with the standards required by Brazilian legislation on beverages. The strawberry and bee honey used in the production of the mixed drink had adequate characteristics for industrial processing, the alcoholic strength of the mixed beverage of honey and strawberry was $10.1^{\circ} \mathrm{GL}$, being within the specifications required by Brazilian legislation. The production of mixed honey and strawberry honey is technically feasible depending on the quality of the product and can be considered as a promising way of harnessing honey in crop surpluses.

Key words: Fermented; Fragaria ananassa; Apis mellifera; Saccharomyces cerevisiae.

\footnotetext{
*Autor para correspondência

Recebido para publicação em 17/08/2016; aprovado em 05/10/2016

${ }^{1}$ Mestranda em Ciência e Tecnologia de Alimentos, UFV, Campus Viçosa-MG, e-mail: rafatrv@yahoo.com.br.

${ }^{2}$ Doutoranda em Engenharia de Processos, UFCG, Campus Campina Grande-PB, e-mail: jessicaleite2010@ gmail.com

${ }^{3}$ Doutoranda em Engenharia de Processos, UFCG, Campus Campina Grande-PB, e-mail: anamarinho06@hotmail.com

${ }^{4}$ Engenheira de Alimentos, UFCG, Campus Pombal-PB, e-mail: marcia_eng.alimentos@hotmail.com
} 


\section{INTRODUÇÃO}

A fermentação de vinhos é proveniente de mostos de uvas, que são utilizadas como matérias-primas principais para produção dessa bebida No entanto, a literatura traz vários estudos que apontam a utilização de diversas frutas na elaboração de bebidas fermentadas, como laranja (OLIVEIRA et al., 2015), abacaxi (PARENTE et al., 2014), jaca (ARQUIERI et al., 2008), amora (FERRI; SANGGIN, 2014).

De acordo com o Decreto $n^{\circ} 6.871$, de 04 de junho de 2009 do Ministério da Agricultura, Pecuária e do Abastecimento (MAPA), que regulamenta a Lei $n^{\circ} 8.918$, de 14 de julho de 1994, fermentado de fruta é a bebida com graduação alcoólica de quatro a quatorze por cento em volume, a vinte graus Celsius, obtida da fermentação alcoólica do mosto de fruta sã, fresca e madura (BRASIL, 2009).

Fermentados, que não são provenientes da uva, devem, obrigatoriamente, ser rotulados com a denominação fermentado acompanhado do nome da fruta da qual se originou (BRASIL, 2009).

O morango é um fruto que apresenta estrutura frágil e alta taxa de atividade respiratória, resultando em uma conservação pós-colheita relativamente curta do fruto in natura (ANTUNES et al., 2007). Os fermentados de frutas como morango não são tão comuns quanto o vinho proveniente da uva, sendo sua produção ainda em escala artesanal no Brasil (CORAZZA et al., 2001). Como o fermentado do pseudofruto de morango é pouco divulgado é interessante o estudo mais aprofundado de sua produção.

Conhecido como ingrediente versátil e altamente fermentescível, o mel de abelha apresenta sabor e aroma característico, promovendo um sabor diferenciado à bebida ou alimento (CRANE, 1987). O alto teor de açúcar do mel inibe o desenvolvimento de micro-organismos, contudo, quando diluído, o mel é fermentado pelas leveduras da espécie Saccharomyces cerevisiae (RIVALDI et al., 2009).

$\mathrm{Na}$ elaboração de fermentado de morango se faz necessário à adição de açúcar ao mosto, a fim de obter uma bebida com graduação alcoólica dentro dos limites estabelecidos pela legislação vigente. Neste trabalho, a fonte de açúcar utilizada foi o mel diluído, já que se trata de um produto de grande abundância na região e de preço acessível. Assim, o presente trabalho teve como objetivo produzir uma bebida mista de mel de abelha e morango, com teor alcoólico de $10^{\circ} \mathrm{GL}$ avaliando a cinética de fermentação alcoólica na produção da bebida.

\section{MATERIAL E MÉTODOS}

\section{Matéria prima}

As matérias-primas utilizadas na produção da bebida mista foram mel de abelha (Apis mellifera) e morangos (Fragaria ananassa), adquiridos no supermercado da cidade de Sousa, Paraíba, posteriormente, conduzidos cerca de 50 km, ao Laboratório de Operações Unitárias e Fenômenos de Transporte, do Centro de Ciências e Tecnologia Agroalimentar da Universidade Federal de Campina Grande, Campus Pombal (PB), onde foi realizado todo o processo fermentativo.

\section{Seleção e sanitização}

Os morangos foram selecionados, classificados, lavados em água corrente, logo após foram sanitizados em solução de 200 ppm de cloro ativo por 15 minutos e enxaguados com água duplamente filtrada. Os frutos foram submetidos ao corte em rodelas.

\section{Preparo do mosto}

O preparo do mosto foi realizado mediante diluição do mel, com água potável da rede pública duplamente filtrada, em filtro de carvão ativado e filtro de polipropileno (com retenção de partículas de 5-15 $\mu \mathrm{m}$ ). O mel foi diluído para um teor de sólidos solúveis igual a 20,4\%. Em seguida, cerca de $900 \mathrm{~g}$ de fatias de morangos foram inseridas no fundo do biorreator, previamente sanitizado, juntamente com $4 \mathrm{~L}$ de mosto.

\section{Sulfitação e Inoculação}

Ao mosto contendo mel de abelha diluído e fatias em rodelas de morango foram adicionados $100 \mathrm{ppm}$ de metabissulfito de sódio, após 10 minutos foi adicionado $1 \mathrm{~g}$ de nutriente. Após 2 horas da adição do metabissulfito e nutriente, a levedura (S. cerevisiae CA11) ativada foi adicionada ao processo. A ativação da levedura CA11 foi realizada paralelamente ao preparo do mosto a ser fermentado e com o auxílio, de água a $40{ }^{\circ} \mathrm{C}$ e uma pequena alíquota de mosto.

\section{Fermentação}

A fermentação foi realizada em reator de polietileno com capacidade de 10 litros. Durante o processo fermentativo foram coletados $100 \mathrm{~mL}$ do mosto a cada 24 horas para proceder as análises.

\section{Trasfega}

Após o processo fermentativo foi realizada a transferência do mosto de uma unidade reatora para outra, esse processo foi feito para eliminar a massa decantada e os frutos suspensos.

\section{Clarificação}

O processo de clarificação foi determinado através de adição de argila do tipo bentonita ao mosto. Cerca de 1,68 g de argila foi diluído em $100 \mathrm{~mL}$ de água. Logo após, a argila foi agitada a cada $2 \mathrm{~h}$ por um período de $24 \mathrm{hs}$, esse procedimento foi realizado para evitar a precipitação da argila.

\section{Envase e rotulagem}

O envase da bebida fermentada foi realizado em garrafas de vidros higienizadas com solução de cloro ativo a 400ppm. Após esse processo foi efetuado o fechamento das mesmas com rolhas de madeiras. Os rótulos foram confeccionados em gráfica local.

\section{Armazenamento}

$\mathrm{O}$ armazenamento foi realizado a temperatura ambiente no Laboratório de Operações Unitárias e Fenômenos de Transporte.

A Figura 1 destaca detalhadamente a sequência das etapas realizadas para o preparo da bebida mista de mel com morango. 
Figura 1. Diagrama de elaboração da bebida mista de mel de abelha e morango. CCTA/UFCG, Pombal, Paraíba.

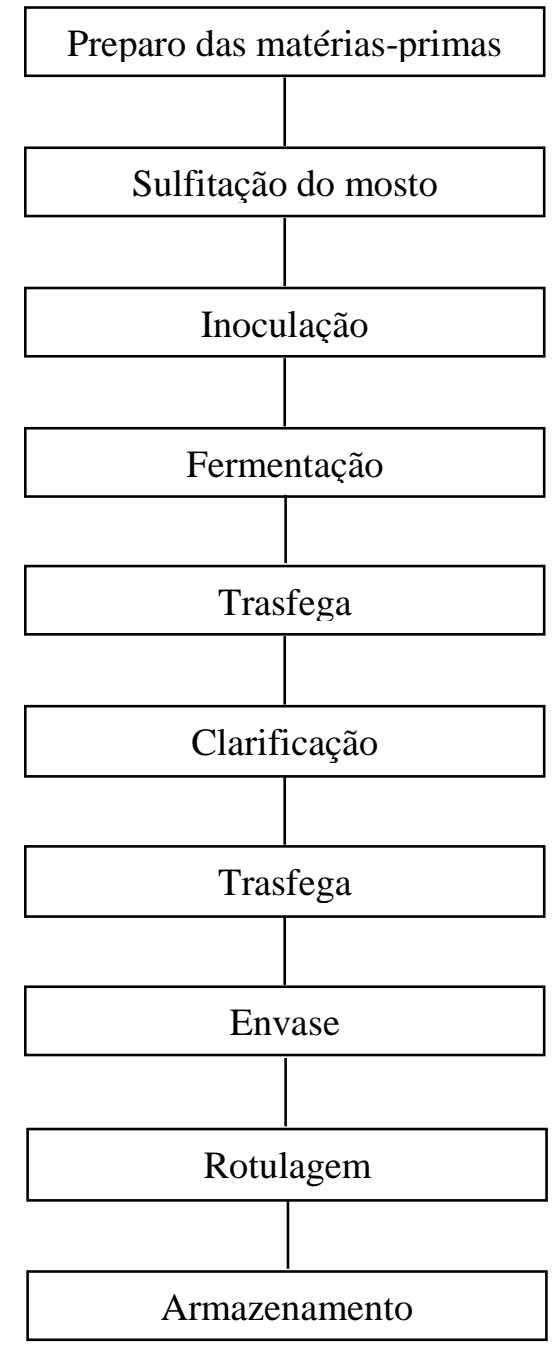

O processo fermentativo para a produção de bebida mista de mel de abelha e morango foi avaliado quanto ao teor de sólidos solúveis totais, produção de etanol, acidez titulável, potencial hidrogeniônico e contagem de células. Foram avaliados oito tempos de fermentação $(0,24,48,96,120,144$, 168 e 192 horas).

As análises físico-químicas foram realizadas no Laboratório de Análise de Alimentos do Centro de Ciências e Tecnologia Agroalimentar da Universidade Federal de Campina Grande, Campus de Pombal, segundo as metodologias de sólidos solúveis, contagem de células, teor alcoólico, acidez titulável e potencial hidrogeniônico.

\section{Contagem de Células}

Determinada por densidade ótica com leitura a $600 \mathrm{~nm}$, em espectrofotômetro da marca Spectrum modelo SP-1105, seguindo o método de Deshpande e Shonnard (1999).

\section{Sólidos Solúveis}

$\mathrm{O}$ teor de sólidos solúveis foi determinado em refratômetro digital com compensação automática de temperatura modelo (AR-200, Reichert).

\section{Teor Alcoólico}

O teor alcoólico foi determinado por ebuliometria. De início se faz a calibração do ebuliômetro. Para tanto, o condensador do ebuliômetro é cheio com água fria, o queimador é aceso e colocados diretamente sob o braço do ebuliômetro. Uma vez que a água ferve e a leitura da temperatura mantém-se estável, observa-se a temperatura e associa-se a $0^{\circ} \mathrm{GL}$ na régua de acompanha o equipamento. $\mathrm{O}$ processo é repetido com a amostra de fermentado. Verificouse a temperatura em que a leitura permanece constante. $\mathrm{Na}$ régua, verificar a graduação alcoólica referente a temperatura de ebulição determinada (JACOBSON, 2006).

Sabendo que $1^{\circ} \mathrm{GL}$ equivalente a $1 \%$ de etanol, que por sua vez equivale a $1 \mathrm{~mL} / 100 \mathrm{~mL}$, a concentração de etanol expressa em $\mathrm{g} / \mathrm{L}$ foi obtida a partir da graduação alcoólica na escala Gay Lussac ( $\left.{ }^{\circ} \mathrm{GL}\right)$ (Equações 1, 2 e 3 ).

$$
\begin{aligned}
& 1^{o} G L \rightarrow 1 \% \text { de Etanol } \rightarrow \frac{1 m L}{100 m L}=\frac{1^{o} G L}{100} \\
& P(g / L)=\rho_{\text {Álcool }}\left(\frac{g}{m L}\right) \times\left(\frac{{ }^{o} G L}{100}\right) x I\left(\frac{L}{L}\right) \\
& P(g / L)=0,7895\left(\frac{\mathrm{g}}{\mathrm{mL}}\right) \times \frac{{ }^{\circ} \mathrm{GL}}{100} \times \frac{1000}{1}\left(\frac{\mathrm{mL}}{\mathrm{L}}\right)
\end{aligned}
$$

Onde:

$\mathrm{P}$ - Concentração de etanol (g/L);

p.́rcool - Densidade específica do etanol $(0,7895 \mathrm{~g} / \mathrm{mL})$.

\section{Acidez Titulável}

Foi determinada através de $5 \mathrm{~mL}$ de mosto e $45 \mathrm{~mL}$ de água destilada acrescido de duas gotas de fenolftaleína alcoólica $1 \%$. Após a homogeneização foi realizada titulação com solução de hidróxido de sódio $(\mathrm{NaOH}, 0,1 \mathrm{M})$, até atingir o ponto de viragem com coloração rósea permanente. Os cálculos da acidez total titulável foi expressa como porcentagem do ácido abundante no morango equivalente à quantidade de $\mathrm{NaOH} 0,1 \mathrm{~N}$ gasto na titulação, conforme as normas do Instituto Adolfo Lutz (2008).

\section{Potencial Hidrogeniônico}

O potencial hidrogeniônico foi determinado por imersão direta do eletrodo nas amostras com auxílio de um pHmetro digital modelo (DM-22) calibrado com solução tampão. A análise foi realizada em três repetições por tempo de análise.

\section{Obtenção dos dados}

Para obtenção dos gráficos, os dados foram tabulados no software Microsoft Excel 2007.

\section{RESULTADOS E DISCUSSÃO}

O comportamento cinético da concentração celular, dos sólidos solúveis (substrato) e etanol (produto) em função do tempo de fermentação podem ser observados nas Figuras 2, 3 e 4, representando as principais variáveis do processo fermentativo.

$\mathrm{O}$ aumento na contagem de células (Figura 2) reflete o comportamento de crescimento padrão dos microrganismos, onde, de início, se tem uma face exponencial de crescimento, seguida por um declínio de crescimento, caracterizando a morte celular. 
Figura 2. Concentração celular de extrato da bebida mista de mel de abelha e morango medido em intervalos de $24 \mathrm{hs}$. CCTA/UFCG, Pombal, Paraíba.

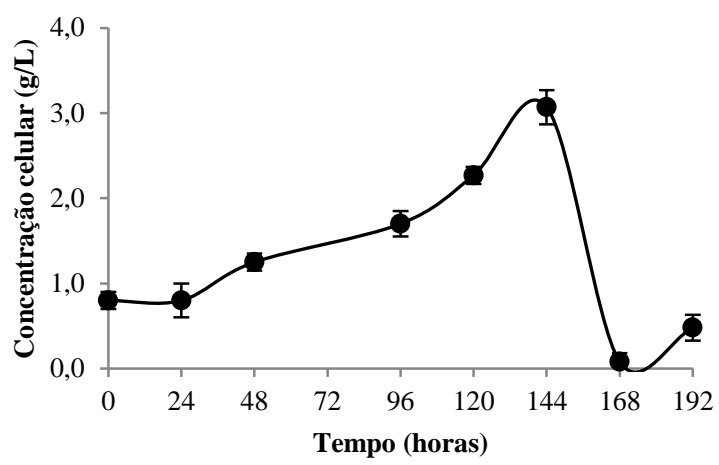

Os teores de sólidos solúveis no mosto reduziram de 20,4 até $8,0 \%$ devido principalmente ao consumo destes durante o tempo de fermentação (Figura 3). Este comportamento foi confirmado pelo aumento do teor de álcool quantificado (Figura 4), resultante da atividade de fermentação das leveduras. Valor próximo foi obtido por Andrade et al. (2014), que ao avaliar o fermentado de morango obteve $8,0 \%$ de sólidos solúveis.

Figura 3. Sólidos solúveis de extrato da bebida mista de mel de abelha e morango medido em intervalos de 24hs. CCTA/UFCG, Pombal, Paraíba.

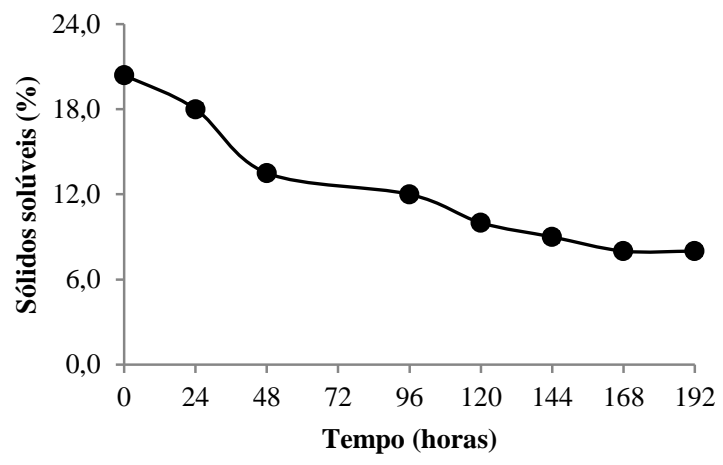

A bebida mista obteve $10,1^{\circ} \mathrm{GL}$ (Figura 4), valor bem próximo ao determinado por Kempka e Mantovani (2013), que obteve $10^{\circ} \mathrm{GL}$ para hidromel produzido a base de mel de angico e pólen. Como também próximo ao valor obtido por Corazza et al. (2001), que obteve um fermentado de laranja com teor alcoólico de $10,6{ }^{\circ} \mathrm{GL}$.

Figura 4. Teor alcoólico de extrato da bebida mista de mel de abelha e morango medido em intervalos de $24 \mathrm{hs}$. CCTA/UFCG, Pombal, Paraíba.

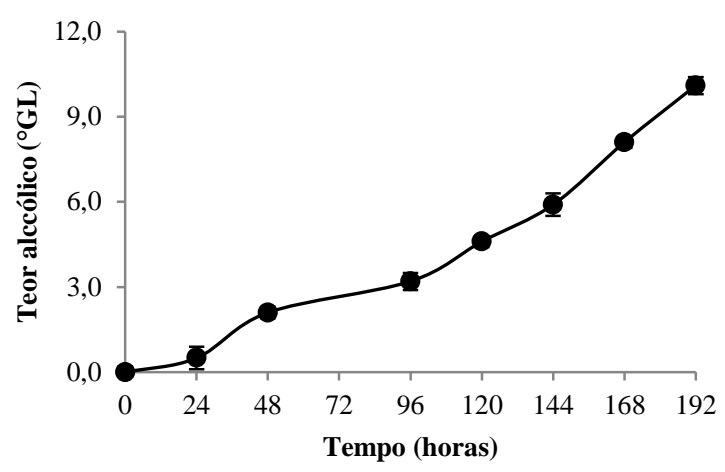

O acúmulo de acidez titulável (Figura 5) reforça o comportamento fermentativo do mosto, também, verificado pela concentração de íons $\mathrm{H}+$, visualizado pelos valores de pH (Figura 6), que aumentou com o tempo de fermentação. Possivelmente, devido à formação de ácidos orgânicos, como ácido lático, acético e succínico (BORZANI et al., 1983), além de glicerina, $\mathrm{CO}_{2}$ e outros compostos que contribuíram para redução do $\mathrm{pH}$.

Figura 5. Acidez titulável de extrato da bebida mista de mel de abelha e morango medido em intervalos de $24 \mathrm{hs}$. CCTA/UFCG, Pombal, Paraíba.

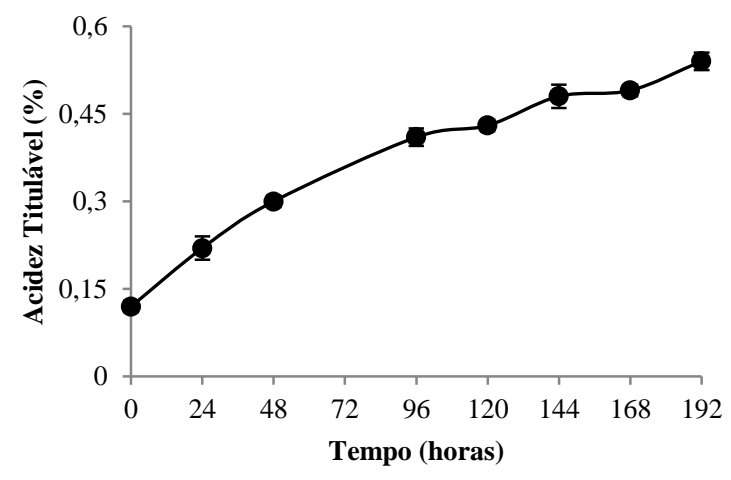

$\mathrm{O} \mathrm{pH}$ encontrado para a bebida mista de mel de abelha e morango ao final do processo fermentativo, foi de 3,18, valor próximo ao observado por Kempka e Mantovani (2013), que encontrou $\mathrm{pH}$ de 3,54 para o hidromel. Também valores próximos foram determinados por Silva (1998) ao avaliar fermentado de caju.

Figura 6. $\mathrm{pH}$ de extrato da bebida mista de mel de abelha e morango medido em intervalos de 24hs. CCTA/UFCG, Pombal, Paraíba.

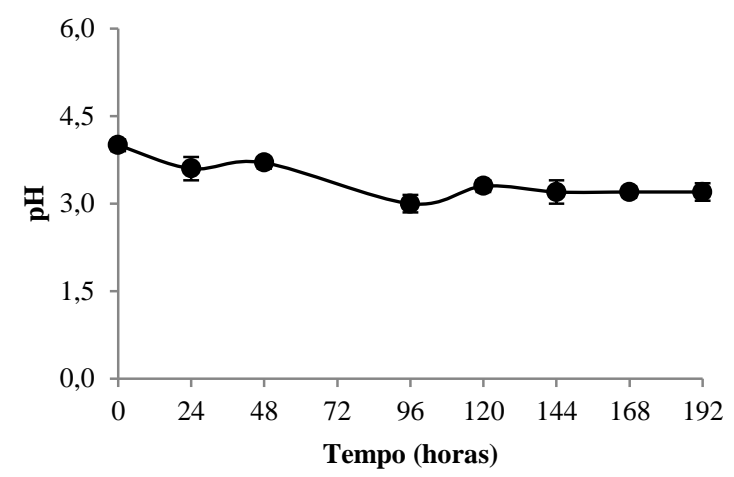

Para a produção da bebida mista de mel de abelha e morango, foi preparado inicialmente $4 \mathrm{~L}$ de mosto, obtendo ao final do processo fermentativo, $2,5 \mathrm{~L}$ de bebida, o que demonstra um rendimento de $62,5 \%$. O baixo rendimento pode ser decorrente da retirada de $100 \mathrm{ml}$ de mosto por tempo de análise (a cada 24 horas) totalizando cerca de $900 \mathrm{ml}$.

Bebida mista de mel de abelha e morango apresentou resultados aceitáveis, sendo uma bebida de cor e aroma característico de mel de abelha e morango (Figura 7). 
Figura 7. Bebida mista de mel de abelha e morango. CCTA/UFCG, Pombal, Paraíba.

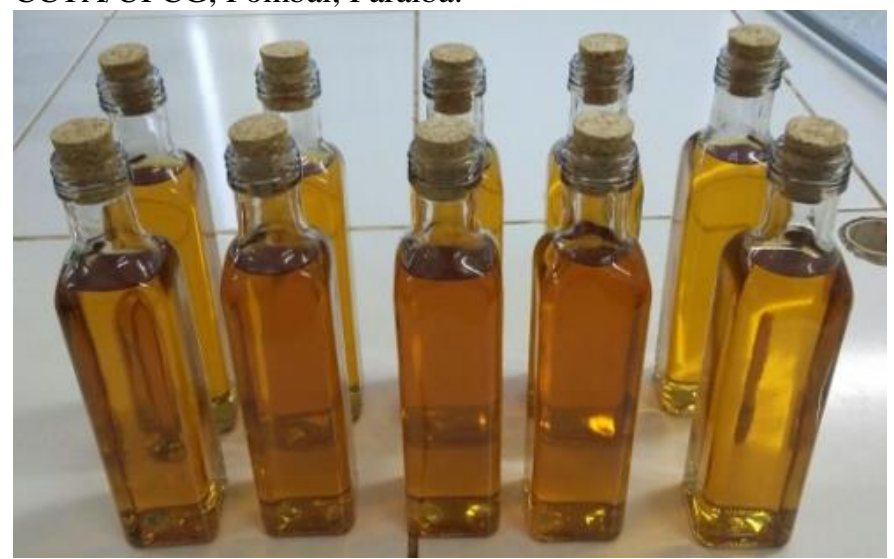

Fonte: Autora (2017).

\section{CONCLUSÕES}

A graduação alcoólica da bebida mista de mel de abelha e morango foi de $10,1^{\circ} \mathrm{GL}$, estando dentro das especificações exigidas pela legislação brasileira.

A produção de bebida mista de mel de abelha e morango é tecnicamente viável em função da qualidade do produto, e pode ser considerada como uma forma promissora de aproveitamento do mel nos excedentes da safra.

\section{REFERÊNCIAS}

ANDRADE, M. B.; PERIM, G. A.; SANTOS, T. R. T.; MARQUES, R. G. Physical and Chemical Characterization of Strawberry Unfermented. Biochemistry and biotechnology reports, v.3, n.1, p. 18-25, 2014.

ANTUNES, L. E. C.; DUARTE FILHO, J. D.; CALEGARIO, F. F.; COSTA, H.; REISSER JUNIOR, C. Produção integrada de morango (PIMo) no Brasil. In: Morango: Conquistando novas fronteiras. Informe Agropecuário: Belo Horizonte, v.28, n.236, p.34-39, 2007.

ASQUIERI, E. R.; RABÊLO, A. M. S.; SILVA, A. G. M. Fermentado de jaca: estudo das características físico-químicas e sensoriais. Ciência e Tecnologia de Alimentos, Campinas, v. 28 , n. 4 , p. 881-887, 2008.

BORZANI, W., AQUARONE, E., LIMA, U. A. Engenharia bioquímica, v.3. São Paulo. 1983.

BRASIL. Decreto n.6871 de 4 de junho de 2009. Regulamenta a lei n.8918 de 14 de julho de 1994, que dispõe sobre a padronização, a classificação, o registro, a inspeção, a padronização e a fiscalização de bebidas. Diário Oficial da República Federativa do Brasil, Brasília, p.20, 5 de jun. 2009.

CORAZZA, M. L.; RODRIGUES, D. G.; NOZAKI, J. Preparação e caracterização do vinho de laranja. Química Nova, São Paulo, v.24, n.4, p.449-452, 2001.

CRANE, E. O livro do mel. 2. ed. São Paulo: Nobel, 1987. $226 \mathrm{p}$.
DESHPANDE, P. A.; AND D. R. SHONNARD. Modeling the effects of systematic variation in ionic strength on the attachment kinetics of Pseudomonas fluorescens UPER-1 in saturated sand columns, Water Resour. Res, v.35, n.5, 1999.

FERRI, M. J.; SAGGIN, R. Elaboração de fermentado alcoólico de amora preta (Rubus spp.) com mel de abelha (Apis mellifera). 2014. 36f. Trabalho de Conclusão de Curso, Universidade Tecnológica Federal do Paraná. Pato Branco, 2014.

INSTITUTO ADOLFO LUTZ. Normas analíticas do Instituto Adolfo Lutz. 4ª Ed. São Paulo: IAL, 2008.

JACOBSON, J. L. Introduction to Wine Laboratory Practices and Procedures. 2006.

KEMPKA, A. P; MANTOVANI, G. Z. Produção de hidromel utilizando méis de diferentes qualidades. Revista Brasileira de Produtos Agroindustriais, Campina Grande, v.15, n.3, p.273$281,2013$.

OLIVEIRA, J. P. .; SILVA NETO, J. C.; SILVA, S. S.; SANTOS, A. S. Produção de fermentado alcoólico de laranja. Revista Verde de Agroecologia e Desenvolvimento Sustentável, Pombal, v. 10, n.3, p 35 - 41, 2015.

PARENTE, G. L.; ALMEIDA M. M.; SILVA, J. L.; SILVA, C. G.; ALVES, M. F. Cinética da produção do fermentado alcoólico de abacaxi 'pérola' e caracterização da bebida. Revista Verde de Agroecologia e Desenvolvimento Sustentável, Pombal, v 9. , n. 2 , p. 230 - 247, 2014.

RIVALDI， J. D; SILVA, M. M; COELHO, T. C.; OLIVEIRA, C. T.; MANCILHA, I. M. Caracterização e perfil sensorial de hidromel produzido por Saccharomyces cerevisiae IZ 888. Braz. J. Food Technol.,VII BMCFB, 2009.

SILVA, F. L. H. Modelagem, simulação e controle de fermentação alcoólica contínua extrativa. Campinas 1998, 162p. Tese (Doutorado) - Faculdade de Engenharia de Alimentos, Universidade Estadual de Campinas (UNICAMP). 